Tempo Social; Rev. Sociol. USP, S. Paulo, 13(1): 39-47, maio de 2001.

\title{
Dos riscos que se corre nas ciências sociais
}

\author{
GABRIEL COHN
}

RESUMO: Os argumentos expostos em Aula Inaugural do curso de graduação em Ciências Sociais no ano 2001 são apresentados, com algumas referências à intervenção feita pelo autor no debate sobre "Pós-graduação e Pesquisa" no recém-realizado I Fórum de Discussão de Políticas Universitárias da USP.

PALAVRAS-CHAVE: ciências sociais, universidade pública, educação, graduação.

ocês estão cheios de orgulho por estarem na universidade pública - a maior e mais importante do país, a que tem a mais forte tradição nas ciências sociais. Se não estão, teriam motivos de sobra para estarem. Afinal, chegaram aqui por um caminho árduo, especialmente para os que sentem dentro de si a chama da vocação para enfrentar reflexivamente a sociedade em que vivem (o que mais do que nunca significa dizer: o mundo). Por que é mais árduo para estes? Porque tiveram que enfrentar todas as dúvidas internas e as resistências externas ("Fazer ciências sociais e morrer de fome? Só há uma coisa que sociólogo pode ser: presidente da República") que cercam a nossa área de conhecimento. Poderiam, afinal, ter feito outras opções, talvez mais seguras, ou mesmo mais fascinantes.

Quanto ao primeiro ponto, reconheço que as garantias que o diploma de graduação em Ciências Sociais (que oficialmente confere ao portador a condição de sociólogo) oferece no mercado de trabalho são das mais tênues. Isto só indiretamente tem a ver com a qualidade do curso ou a capacidade dos graduados (mas em ambos os pontos devemos sempre

Professor do Departamento de Ciência Política da FFLCH - USP 
exigir o máximo, como insistirei mais à frente). Deve-se muito mais a duas circunstâncias, cuja presença se acentuou desde os anos 70 do século passado. A primeira é a degradação dessa coisa importantíssima que é a escola pública de segundo grau, que absorvia graduados em ciências sociais, não como sociólogos estritamente, mas para lecionar em áreas afins. (Diga-se de passagem que é uma tarefa política urgente a recuperação da consciência pública de que a dedicação ao ensino de segundo grau é tarefa fundamental e honrosa, e que à USP cabe retomar sua vocação de formar os formadores de cidadãos). A segunda diz respeito à criação de nichos artificiais no mercado de trabalho mediante a regulamentação de profissões em áreas como jornalismo, propaganda e tantas outras. Isto está ligado à expansão das escolas superiores privadas, que ameaçam promover no ensino superior o que suas congêneres ajudaram a fazer no ensino de grau médio, tão degradado que a própria profissão de professor ficou aviltada, chegando quase a ser motivo de vergonha. Estas empresas de ensino não demoraram a perceber o filão constituído pelos mercados cativos de candidatos a profissões dependentes dos diplomas que elas se prontificariam a oferecer. O resultado foi o fechamento gradativo de portas para os graduados em ciências sociais, que se distinguiam pela suas capacidades múltiplas e inteligência flexível.

Diante desse quadro a resposta estudantil, e da universidade como um todo, só pode ser uma: ir mais fundo. Isto significa tomar, ou recuperar, a iniciativa da universidade pública na definição das áreas e formas de atuação em que vai concentrar seus esforços, com base nas exigências de democracia política, de avanço econômico e científico-tecnológico e de expansão cultural que detecta na sociedade. Em suma: procurar por todas as formas a excelência. Nessa tarefa de detectar o que o momento histórico da sociedade exige nós das ciências sociais talvez possamos ajudar, cada um do seu modo. O preparo para tanto passa por muitas dimensões. Uma delas consiste na capacidade dos estudantes de absorver ao máximo o que lhes é oferecido na USP (a começar, é claro, pelo seu curso, mas não só nele: basta olhar por aí para ver quanta coisa ocorre diariamente neste campus). Se antes cabeças ágeis competiam bem num mercado de trabalho mais aberto, hoje, em condições mais difíceis, é preciso ser ainda mais atento e diferenciado, para não se acomodar e já entrar derrotado em campo. Quanto às antigas aspirações políticas à mudança total da sociedade, encontram-se despedaçadas pelo rumo da história. Mas há pedaços bem interessantes, e o jogo da recombinação entre eles mal começou. Seria idiota e de má fé dizerlhes que os tempos são fáceis (alguma vez foram?), mas seria outro tanto aceitar que a posição do estudante de ciências sociais é de saída pior que a de quaisquer outros. Mas certamente não é melhor. Parece-me ver sinais da busca, entre estudantes de várias áreas, de novas formas de organização para melhor enfrentarem as novas condições da sociedade. Desconfio que habilitar-se a melhor conhecer essa sociedade só pode ajudar. 
Quanto ao segundo ponto tenho posição antiga e firme, mas reconheço minha escassa imparcialidade. Para mim as ciências sociais (no sentido do estudo das formas de sociabilidade, de cultura e de poder) são fascinantes, sim, e tanto quanto qualquer outra área de interesse e de atividade. Mas não substituem as outras, pelo contrário. Seu fascínio só se realiza plenamente na sua capacidade de chamar a atenção para tudo o que nos cerca, e por fazê-lo de modos próprios e inconfundíveis: antropologicamente, sociologicamente, politicamente (para só ficarmos dentro deste prédio) mas também de mil outras maneiras. Essa coisa complicada que o grande mestre norte-americano C. Wright Mills denominava "imaginação sociológica" passa por muitos modos de experiência. Envolve curiosidade, atenção focalizada, mobilidade (esta dimensão é decisiva, e talvez sintetize todo o resto), culminando na lenta e sempre renovada formação de uma inteligência alerta e reflexiva (crítica, portanto, sem ser casmurra; e sensível, sem ser sentimental).

Acabo de usar termos decisivos: "experiência" e "formação". Ambos me fascinam, e me escapam sempre que tento capturar inteiro o seu sentido. Não admira que assim seja: designam modos de mudança, não de permanência. Vocês se admirarão de ver quanto isso é freqüente nas ciências sociais: tudo é percurso, a experiência é móvel, os conceitos que buscam aderir a ela ficam para trás, é preciso sempre reconstrui-los. Um pouco neste sentido Max Weber, cuja sombra gigantesca projeta-se sobre a sociologia e a análise política de todo o século 20, dizia que as ciências sociais (ele preferia dizer "da cultura", porque lhe importavam antes de mais nada os significados) estão condenadas à "eterna juventude". Dito por ele isso fazia referência a algo fundamental: o que envelhece e o que sempre se cria de novo não são coisas ou sequer conceitos, são problemas. É o modo como interrogamos o mundo que se renova sempre. E, se pensarmos as ciências como campos de interrogações, são elas que se renovam. O termo "interrogar" apresenta-se aqui no seu sentido mais forte, de questionar, de pôr em questão, de relacionar-se com nossas inquietações mais fundas (de novo introduzo um termo chave, mais uma dessas expressões que sintetizam a condição de sociólogo, para usar o termo mais abrangente na área: inquietação, a outra face da mobilidade a que já me referi). É um pouco disso que deriva a afinidade entre o grande cientista social e o grande jornalista, e de ambos com o grande romancista, as diferenças básicas consistindo no caminho adotado (no método) e no modo de controle da relação entre realidade efetiva e ficção - ou seja, da relação entre o que está dado à observação sem mais, "ingênua", e os artifícios que se inventam para encontrar nela um sentido compartilhado (no relato comentado, ou no conhecimento metodicamente bem fundado, ou na "fantasia exata" da obra).

Como esses pontos relacionam-se com a experiência? De todos os modos, da maneira mais íntima, e em todos os níveis de significa- 
do do termo. Permitam-me, neste ponto, fazer um pouco de "etimologia caseira", bem pouco fundamentada, sobre o termo "experiência". Impressiona-me nele a junção de referências muito expressivas. No seu centro está uma raiz (per) que passa pelo latim e relaciona-se com noções como "risco", estando presente, por exemplo, em "perigo". Experimentar é então arriscar-se. Mas o ponto que verdadeiramente me fascina (e onde abandono toda a prudência científica) consiste na presença do prefixo ex, que modifica decisivamente a referência ao risco. Remete àquilo sem o que a experiência não se dá. Designa o risco que se enfrenta ao sair para o exterior, abandonando a segurança interna e a quietude acomodada para o exercício dessa inquietação que leva a sair de si e a expor a face ao mundo. Vivência do mundo e conhecimento do que nele se encontra conjugam-se exemplarmente no termo experiência. Ela não se faz sem vencer o medo e exercer a inquietação, este acicate a uma mobilidade que só se põe no compasso do movimento do mundo quando se expõe a ele para interrogá-lo. Para interrogá-lo: mantendo portanto a iniciativa, não se perdendo, certificando-se que enfrentar riscos envolve conhecer o caminho do retorno (o método é um via de duas mãos). Não dramatizemos demais, portanto: experiência não é o mesmo que êxtase, não é lançar-se perdidamente mas encerra, em graus variados, o momento decisivo da reflexão.

Tomada em toda a sua riqueza a experiência apresenta-se na forma de complexos significativos densos, nos quais se condensam trajetórias que as artes são capazes de acompanhar mas que as ciências não têm como enfrentar. Para exercer o seu mister estas não dispensam uma "filtragem" prévia, em que, ao passar pelo crivo do exercício metódico da razão, a experiência se converte em pesquisa. Simultaneamente tímida e atrevida, a pesquisa tateia, ensaia, "experimenta" com a mescla de curiosidade implacável e de reflexão disciplinada que lhe é própria. Há nela um irredutível traço infantil que, contido pelas severas exigências da busca do conhecimento, sobrevive no componente lúdico sem o qual não há ciência, como lembrava Adorno - o mesmo Adorno, aliás, que tinha como uma de suas referências básicas a idéia de uma relação do homem com o mundo que não fosse da ordem do enfrentar-se o "objeto" por um "sujeito" obstinado e endurecido mas da ordem do aconchegar-se, da aproximação não possessiva. Inquietação, mobilidade, perguntas atiladas, respostas bem urdidas - estamos diante de um jogo? Não tanto. Mas certamente diante de um aprendizado, de um processo de formação, enfim.

Se o tema da experiência vai tão fundo quanto essas observações tentam sugerir, e acaba entrelaçando-se com o da formação, o que dizer desta? Neste ponto estamos no centro mesmo da idéia da universidade moderna, desenvolvida na Europa da transição do século XVIII para o XIX num fecundo intercâmbio entre as idéias científicas em plena expansão e as concepções humanistas inspiradas tanto pelas promes- 
sas quanto pelas insuficiências da Ilustração. A idéia subjacente é a da constituição, pela experiência de vida assimilada reflexivamente, da plenitude dos dons e habilidades de uma personalidade completa. A universidade (e aqui se leva a sério o seu nome) seria o local onde se concentram as condições para tanto. Nisso vai intrínseca a tensão entre o impulso à universalidade e as máximas prudentes do adestramento competente num ofício útil. A universidade digna desse nome nunca se livrará desse conflito interno insolúvel, que a instiga e lhe dá energia. Inaceitável é considerá-lo superável ou, ainda pior, já superado em nome desse ou daquele dos pólos opostos - como se fossem separáveis, como fossem mais (ou menos) do que as formas que assume a interminável cobrança da promessa inscrita no nome universidade. Vocês, se estiverem atentos, sentirão desde o começo as reverberações dessa luta surda, e compreenderão que enfrentá-la é tarefa para uma vida, não necessariamente aquela que escolherão para si. Mas, seja qual for o seu rumo, suas vidas serão mais pobres se vocês ficarem insensíveis àquilo que imanta o local em que agora estão.

Há algo no problema da junção das duas faces do problema dos estudos superiores, a da formação e a do adestramento, que me parece de especial importância no caso das ciências sociais (nas outras áreas não tenho como avaliar seu peso). Refiro-me a uma característica básica do conhecimento da vida social: a de que nele pouco se avança quando se tenta obter resultados por via direta, na confrontação ombro a ombro com o objeto. É preciso aprender a usar caminhos mais longos, às vezes tortuosos, para chegar aos matizes de significado que dão seu colorido próprio às formas de aproximação, de afastamento, de conflito entre grupos humanos de que é feito nosso campo de estudos. Mas "aprender a usar caminhos", retos ou não, tem nome: é método. É este que permite abrir as portas do conhecimento sem precisar arrombá-las a pancadas ou permanecer vacilante e desorientado diante delas. Sem o rigor do método, portanto, nada feito. Mas só com ele também não se vai longe.

O problema não é novo. Ele encontrou formulação modelar no século XVII, nas palavras de quem tinha plena autoridade para fazêlo, esse notável representante do "século do gênio" que foi Blaise Pascal. Refiro-me à sua distinção entre o "espírito de geometria", do rigor, e o "espírito de finesse", da finura. Rigor e finura: sem o concurso de ambas não há como bem formular os problemas, nem como orientar-se nas intrincadas vias da sua solução. Trabalhar bem com ambas essas dimensões é um dos maiores desafios da formação universitária. E usei o termo formação de propósito. Pois é a preocupação com a junção do rigor com a finura que mais nitidamente separa a formação do adestramento especializado, do training. Os modelos europeus do início do século XX que inspiraram a USP na sua fase de implantação (basicamente o francês e o alemão, com o primeiro 
incidindo mais nas "humanas" e o segundo nas "exatas") contemplavam a questão da formação. O modelo norte-americano, que aos poucos foi se instalando e vai se tornando hegemônico, tem como foco a idéia do training. É claro que em nenhum dos casos a adesão a um pólo da questão é exclusiva. (O colega Cícero Araújo, aqui presente, contava há dias como a instituição norte-americana de primeira linha da qual acaba de retornar, o MIT, encontrou formas engenhosas para enfrentar a questão. Na pós-graduação, claro, pois a graduação para eles não pesa. E o colega Leopoldo Waizbort, também presente, tem interessantes reflexões sobre temas como o da "interdisciplinaridade", baseadas na sua experiência combinada de USP e universidades alemãs). Mas ninguém conseguiu, até hoje, enfrentar a fundo a questão da articulação entre rigor e finura, entre adestramento e formação - a questão, enfim, de como converter a universidade no ambiente mais propício ao aprendizado e ao exercício de formas de inteligência capazes de associar as mais severas exigências da atividade analítica com a capacidade de perceber relações finas que escapem das malhas dos mais poderosos esquemas formais. Pois, afinal, pouco mais pode-se exigir da ciência do que a descoberta metódica de relações não triviais entre fenômenos. Nas ciências sociais há ainda a considerar uma face peculiar da sua "eterna juventude". Consiste ela no seu apego aos clássi$\cos$, no seu sempre renovado retorno a certas contribuições dos grandes mestres que operam como se fossem prismas, sempre prontos a refratar de novos modos a luz dos problemas que se vão revelando importantes ao longo do tempo. A peculiaridade disso vai além da contumaz desobediência à sentença do matemático e filósofo Whitehead, de que "uma ciência que hesita em esquecer os seus clássicos está morta". É que os argumentos propostos ao longo das grandes obras e o modo que nelas se mobiliza a pesquisa e se encadeiam problemas acabam pesando tanto ou às vezes até mais do que os resultados pontuais nelas alcançados. Este é o modo como as ciências sociais fazem justiça à condição de toda ciência, de ser mais a arte de fazer bem a boa pergunta ao aspecto do mundo que tem em vista do que a técnica de oferecer respostas aceitáveis - por mais que, de novo, sejam pólos que não vivem um sem o outro.

Conciliar rigor e finura, unir a sutileza da pergunta à destreza da resposta. Sem dúvida isso compõe um grande desafio. Mas, por que formulá-lo com referência tão explícita à universidade pública? Porque é nela que se põe de maneira decisiva a questão da excelência. Nenhuma exigência é alta demais para a universidade que deve servir de padrão de desempenho para o conjunto do ensino superior - mesmo porque se isto for deixado para o setor privado a degradação é certa, e as escolas que buscam firmar sua posição na faixa das "públicas não-estatais", como as PUCs, não podem ser incumbidas desse encargo, embora possam co- 
laborar vigorosamente. Quando falo em excelência estou em primeiro lugar pensando exatamente nisso: o mais alto nível de qualidade em todas as atividades que possa ser atingido nas condições dadas, junto com o empenho em mudar essas condições para melhor, tornando-as assim mais exigentes. Mas penso também na questão prévia, relativa à definição do que vem a ser a excelência no trabalho universitário e dos padrões que permitam discerni-la. Invoco, neste passo, um debate acalorado, ao qual vocês certamente estarão expostos nesses próximos anos. As questões envolvidas são das mais difíceis, e envolvem as mais diversas dimensões das políticas educacionais. Falar em excelência já é complicado; mais difícil é encontrar uma forma de tratar do problema do desempenho (ou seja, da questão sobre quais modalidades de ação geram resultados excelentes). E a dificuldade chega ao ápice quando se trata das formas de avaliação do desempenho. Pois é aqui que se aplicam, de modo mais concreto e com as consequiências práticas mais visíveis, os princípios básicos que identifiquei como "formação" e "adestramento". Claro que a avaliação a que me refiro neste passo vai além do desempenho discente nas suas atividades de aprendizado, e envolve a atividade docente, de pesquisa e tudo o mais que faça parte do trabalho universitário. Mas não é preciso ir longe na análise para perceber que os dois princípios a que me referi, nas formas que assumem em cada caso, atravessam todo o campo das políticas universitárias. Em graus e com nitidez diversos, sem dúvida; principalmente quando se desenha a hegemonia de um deles, como é a situação atual, em que desempenho se traduz em adestramento eficaz e produtividade. Seria então o caso de, em nome da formação relegada para segundo plano, partir para o combate ao binômio adestramento eficiente/competência produtiva? Eu não diria isso. O combate é necessário, sim, contra a dominância unilateral de qualquer um dos princípios. Mas não em nome da mera substituição do dominante, e sim de um passo qualitativo à frente na relação entre eles. Como diria algum frasista de ocasião: o adestramento sem a formação é cego, e a formação sem o adestramento é impotente. Já me acomodei no muro, dirão alguns. Não é bem assim, até porque não escondo meu compromisso com a causa da formação, que considero a real base para todo o resto, mas incapaz de resolver tudo sozinha. Até porque, da fileira de paradoxos que encontramos nesse campo demarcado pela formação e pelo adestramento, destaca-se mais um. É que, por mais que o adestramento envolva a aquisição do domínio sobre um conjunto de técnicas, sobre um vocabulário e sobre uma linguagem bem específicos (não existe competência no geral) ele só ganha pleno sentido quando submetido ao contato com outros vocabulários e outras linguagens. Não para assenhorear-se delas, mas para melhor perceber, no ato mesmo de expor-se a outros modos de pensar, de fazer e de dizer, nuanças da linguagem que supõe dominar (e também o seu alcance e os seus limites). Este 
é um passo em que as preocupações do adestramento eficaz podem enlaçar-se proveitosamente com as preocupações da formação diferenciada, numa retomada do tema da experiência: a inteligência bem adestrada mas que só se aventura em terreno já demarcado e arado e teme o que não domina é, no sentido literal do termo, idiota.

Uma última observação, que me permite retomar por outro ângulo o tema da relação formação/adestramento. Refere-se ela à organização do núcleo das atividades universitárias, como ocorre aqui na USP, em termos de graduação, pós-graduação e pesquisa. Essas três dimensões são vistas como intimamente conectadas. O problema consiste no modo como se concebe essa conexão. O modo convencional, que orienta os debates na universidade (estou pensando no exemplo do recente Fórum da USP, em que as questões como a que estou formulando neste ponto foram levantadas), consiste em ver a relação nos seguintes termos: a graduação vinculase à pós-graduação, e esta vincula-se à pesquisa. Isto se reflete no organograma da universidade, que prevê três pró-reitorias nessa área: de graduação, de pós e de pesquisa. A conseqüência mais direta disso, naquilo que nos importa, é que a pós-graduação tem por referência direta a pesquisa e não a graduação, e esta corre o risco de ficar no vazio. Em consonância com tudo o que eu afirmei acima uma articulação alternativa seria mais recomendável: formação (compreendendo os dois passos da graduação) e pesquisa. Ou, como eu próprio formulei em tom provocativo em outra ocasião: se existe Ciência \& Tecnologia, por que não Formação \& Pesquisa? Organizadas desse modo, essas três instâncias básicas da vida universitária poderiam entrar em relações muito mais diferenciadas, talvez fazendo mais justiça à importância intrínseca de cada dimensão: do adestramento e da formação, do rigor e da finura, da produção e do significado do que se produz, da iniciativa e da reflexão, da competência especializada e da inteligência inquieta, da experimentação bem equipada e da experiência bem vivida.

É isso. E mal chegamos ao começo. Desejo-lhes uma experiência fecunda, com resultados excelentes. Obrigado.

Recebido para publicação em março/2001

$\mathrm{COHN}$, Gabriel. Of risks encountered in the social sciences.Tempo Social; Rev. Sociol. USP, S. Paulo, 13(1): 39-47, May 2001. 
COHN, Gabriel. Dos riscos que se corre nas ciências sociais. Tempo Social; Rev. Sociol. USP, S. Paulo, 13(1): 39-47, maio de 2001.

ABSTRACT: The arguments exposed at the Inaugural Lecture of the graduate course in Social Sciences in 2001 are presented with a few references to the intervention made by the author in the debate on 'Post-Graduation and Research' at the I Forum of Discussion on USP's University Policies.

KEY WORDS:

social sciences, public university, education, graduation. 